\title{
A Hybrid Search Algorithm for Midterm Optimal Scheduling of Thermal Power Plants
}

\author{
Shengli Liao, ${ }^{1}$ Chuntian Cheng, ${ }^{1}$ Jing Wang, ${ }^{2}$ and Zhongkai Feng' \\ ${ }^{1}$ Institute of Hydropower and Hydroinformatics, Dalian University of Technology, Dalian 116024, China
}

${ }^{2}$ Huadian Electric Power Research Institute, Hangzhou 310030, China

Correspondence should be addressed to Shengli Liao; shengliliao@dlut.edu.cn

Received 9 September 2014; Revised 7 January 2015; Accepted 26 April 2015

Academic Editor: Andrzej Swierniak

Copyright (c) 2015 Shengli Liao et al. This is an open access article distributed under the Creative Commons Attribution License, which permits unrestricted use, distribution, and reproduction in any medium, provided the original work is properly cited.

A hybrid search algorithm consisting of three stages is presented to solve the midterm schedule for thermal power plants (MTSFTPP) problem, where the primary objective is to achieve equal accumulated operating hours of installed capacity (EAOHIC) for all thermal power plants during the selected period. First, feasible spaces are produced and narrowed based on constraints on the number of units and power load factors. Second, an initial feasible solution is obtained by a heuristic method that considers operating times and boundary conditions. Finally, the progressive optimality algorithm (POA), which we refer to as the vertical search algorithm (VSA), is used to solve the MTSFTPP problem. A method for avoiding convergence to a local minimum, called the lateral search algorithm (LSA), is presented. The LSA provides an updated solution that is used as a new feasible starting point for the next search in the VSA. The combination of the LSA and the VSA is referred to as the hybrid search algorithm (HSA), which is simple and converges quickly to the global minimum. The results of two case studies show that the algorithm is very effective in solving the MTSFTPP problem accurately and in real time.

\section{Introduction}

Electric power generation in China mainly consists of coalfired thermal power plants and hydroelectric power plants $[1,2]$. At the end of 2013, China's total installed generation capacity reached $12473.8 \mathrm{GW}$, with approximately $64.2 \%$ derived from coal-fired thermal power plants, $5 \%$ from thermal power using other fuels (e.g., oil and gas), $22.5 \%$ from hydropower, $6.1 \%$ from wind power, $1.2 \%$ from nuclear power, and the remainder from other sources [2]. However, coal-fired units are difficult to start up and shut down, and they respond slowly to system demand because preheating and cooling of the stream turbines is required. Moreover, startup and shutdown of a coal-fired unit require considerable amounts of fuel [3]. Therefore, thermal plants are usually scheduled to meet the base demand to ensure that the generation process proceeds smoothly and to minimize the startup and shutdown times of thermal units.

Over the past decade, extreme weather events such as storms, droughts, high temperatures, and damaging hail have occurred frequently in China, which has caused the demand on power systems to change substantially from day to day. These large deviations in demand over short periods cause difficulties in the scheduling of the power systems, a problem that is exacerbated by the large number of coal-fired thermal units in use. Consequently, the power dispatch centers in China must determine the optimal midterm schedule for thermal power plants (MTSFTPP), where "midterm" is a period of one to six months, to determine which units to start up and shut down or the boot capacity of every thermal plant each day before determining the short-term and daily schedules.

The midterm schedule is important for the economical operation of power systems. The objective of the scheduling problem is to find the optimal set of thermal generating units in a power system that will satisfy the system demand, operational restrictions, reliability constraints, and security requirements for each period considered. Unlike the shortterm unit commitment problem associated with power systems, which involves determining a startup and shutdown schedule of units to meet the demand over a period of one day to one week, loads must be dispatched to each plant in 
the midterm to allow for maintenance and coordination with hydropower plants. Optimal midterm scheduling smoothes the demand on thermal plants, allowing them to operate more efficiently, and makes the best use of hydropower plants. In contrast with the short-term optimal scheduling of thermal power plants, there has been little research on the midterm problem.

The MTSFTPP problem is a variation of the unit commitment (UC) problem, which is a large-scale, nonlinear, nonconvex, mixed-integer combinatorial optimization problem. Various techniques [4-8] have been used to solve this computationally expensive problem [5]. Among these techniques are dynamic programming (DP) [9-12], branch-andbound (BAB), Lagrangian relaxation (LR) [13-15], integer programming (IP) $[16,17]$, and metaheuristic algorithms such as genetic algorithms (GA) [18-24], particle swarm optimization (PSO), and neural networks [25-27].

Many methods such as DP, BAB, and IP suffer from the curse of dimensionality; that is, the solution space increases exponentially with the number of generating units. As a result, the computation time becomes unacceptable. LR, which decomposes the primal problem into a set of single plant or unit optimization subproblems that are easier to solve independently, has shown potential in solving the UC problem. However, this approach requires the conversion of the optimal dual solution into a feasible solution of the primal problem because of the duality gap, which represents the primary difficulty associated with LR. Metaheuristic algorithms have been widely used to solve the UC problem in recent years, but the quality of the solution depends on the choice of the control parameters, and choosing the control parameters of these algorithms is a very difficult task.

Essentially, the MTSFTPP problem is a multistage (in this context, the term "stage" refers to time) decision problem with unit constraints (type 1), thermal power load factor constraints (type 2), operating time constraints (type 3), and boundary condition constraints (type 4). Considering that types 1 and 2 are single-stage constraints and independent between any two stages, whereas type 4 constraints can be met by the initial solution, the optimization process mainly involves type 3 constraints, which are time constraints. This study investigates a hybrid search algorithm (HSA) to solve the MTSFTPP problem. The primary objective is to achieve equal accumulated operating hours of installed capacity [25] (EAOHIC) for all thermal power plants over a given period, with extra hours that are given to the plants with lower emissions, higher efficiency, and occasional unit maintenance. A more detailed description of the problem is provided in Section 2. Section 3 presents a detailed explanation of the HSA. A case study is presented in Section 4, and conclusions are presented in Section 5.

\section{Problem Formulation}

2.1. Objective Function. Equality, impartiality, and transparency are important in electric power dispatching. Based on power system security, stability, and economics, units should be treated equally in problems involving operations

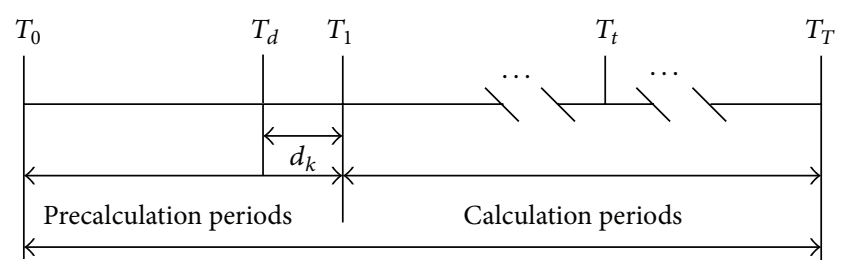

Appointed periods

FIGURE 1: Accumulated operating hours defined from the start of the warm-up period to the end of the computational period (horizon).

management and information disclosure. In many western countries, the driving force behind deregulation is the belief that competitive markets make the industry more efficient, leading to lower costs. In the case of China, similar to other developing countries, the incentive for restructuring is derived from the desire to provide equal opportunities to all participants. In China, the firms established by the government are responsible for power system operations, and the power systems are operated in an integrated fashion. Therefore, equality is usually the main concern in long-term and midterm scheduling in China. In this study, EAOHIC is the primary consideration in the MTSFTPP problem. Operating hours are accumulated from the beginning of the respective warm-up periods to the end of the computational period (Figure 1). The EAOHIC constraint for the MTSFTPP problem is formulated as follows:

$$
H_{i}=H_{j} \quad(i \neq j),
$$

where $H_{i}, H_{j}$ are the accumulated operating hours of installed capacity for plants $i, j$, respectively, in the selected period.

Although the concept captured by (1) is unambiguous and easily understood, the problem is very difficult to solve directly because the formulation is related to all plants and the objective cannot be evaluated by the computation of a single mathematical expression. Considering that the variance can be used to describe the degree of dispersion of data, let $H=$ $\left(H_{1}, H_{2}, \ldots, H_{k}, \ldots, H_{m}\right)$ be the set of accumulated operating hours of the installed capacity for the plants, and let $D(H)$ be the variance of the set $H$. Equation (1) can be replaced by the following problem:

$$
\begin{aligned}
f & =\min D(H), \\
D(H) & =\frac{1}{m} \sum_{k=1}^{m}\left(H_{k}-\bar{H}\right)^{2}, \\
\bar{H} & =\frac{1}{m} \sum_{k=1}^{m} H_{k}, \\
H_{k} & =H_{k p}+H_{k T}-H_{k e}, \\
H_{k T} & =\frac{1}{N_{k}} * \bar{C}_{k} * T * 24 * r, \\
\overline{C_{k}} & =\frac{1}{T} \sum_{t=1}^{T} C_{k t},
\end{aligned}
$$


where the variables are defined as follows: $H$ is the set of $H_{k}$, the accumulated operating hours of the installed capacity of plant $k$ during the selected period, in hours (h); $m$ is the total number of plants; $D(H)$ is the variance of set $H$, in $\mathrm{h}^{2} ; \bar{H}$ is the average of set $H$, in $\mathrm{h} ; H_{k p}$ is the operating hours of installed capacity of plant $k$ accumulated during the warm-up period, in $\mathrm{h} ; H_{k T}$ is the operating hours of installed capacity of plant $k$ accumulated during the computational period, in h; $H_{k e}$ is the extra hours assigned to plant $k$, in $\mathrm{h} ; \mathrm{T}$ is the total number of steps $t$ in the computational period, where each step is one day; $N_{k}$ is the installed capacity of plant $k$, in MW; $\overline{C_{k}}$ is the average of the operating capacity of plant $k$ during the computational period, in MW; $r$ is the load factor; and $C_{k t}$ is the operating capacity of plant $k$ in period $t$, in MW.

2.2. Constraints. Due to the operational requirements, the minimization of the objective function is subject to the following types of constraints.

\section{(1) Unit Constraints. Consider}

$$
u_{t, k}^{\min } \leq u_{t, k} \leq u_{t, k}^{\max }
$$

where $u_{k, t}^{\min }$ and $u_{k, t}^{\max }$ are the minimum and maximum numbers of units, respectively, in plant $k$ in period $t$ and $u_{k, t}$ is the number of active units in plant $k$ in period $t$.

\section{(2) Thermal Power Load Factor Constraints. Consider}

$$
C_{s t} * r^{\min } \leq P_{t} \leq C_{s t} * r^{\max },
$$

where $C_{s t}$ is the operating capacity of the system in period $t$, in $\mathrm{MW}$, and $r^{\mathrm{min}}$ and $r^{\max }$ are the minimum and maximum load factors of thermal power, respectively, which are calculated from the long-term real-world operation of power grid. $P_{t}$ is the demand of system in period $t$, in MW.

(3) Time Constraints. Midterm optimal thermal power plant scheduling only dispatches the system load to the plants and does not distribute the load among the units in each plant. Therefore, we transform the constraints on the response of a plant into minimum-time constraints at minimum or maximum output. Consider

$$
\begin{gathered}
\tau_{k, j}^{\text {peak }} \geq T_{k}^{\text {peak,min }}, \\
\tau_{k, j}^{\text {valley }} \geq T_{k}^{\text {valley,min }},
\end{gathered}
$$

where $\tau_{k, j}^{\text {peak }}$ is the duration of peak $j$ in the output of plant $k$, $T_{k}^{\text {peak,min }}$ is the minimum duration of the peak in the output of plant $k, \tau_{k, j}^{\text {valley }}$ is the duration of valley $j$ in the output of plant $k$, and $T_{k}^{\text {valley,min }}$ is the minimum duration of the valley in the output of plant $k$.

(4) Boundary Condition Constraints. The planning for the current period depends on the previous states of the units. For the plant $k$, considering the previous period $d_{k}$ as the maximum in $T_{k}^{\text {peak,min }}$ and $T_{k}^{\text {valley,min }}$, the states of the units before the starting point affect the operation of the units through the minimum peak and valley time restrictions, as shown in Figure 1. Consider

$$
\begin{gathered}
\tau_{k, 0}^{\text {peak }} \geq T_{k}^{\text {peak,min }}, \\
\tau_{k, 0}^{\text {valley }} \geq T_{k}^{\text {valley,min }},
\end{gathered}
$$

where $\tau_{k, 0}^{\text {peak }}$ and $\tau_{k, 0}^{\text {valley }}$ are the first duration of peak and valley in the output of plant $k$, respectively.

Note that the boundary condition constraints are the same as the time constraints (type 3 ), the time constraints considering the time horizon in $\left[T_{1}, T_{T}\right]$, while the boundary condition constraints considering in $\left[T_{d}, T_{T}\right]$.

\section{Solution Methodology}

The MTSFTPP problem is a UC problem, and each approach to the problem has its disadvantages, as mentioned previously. Constraints of types 1 and 2 involve a single period and can be treated independently to reduce the search space, constraints of type 4 can be satisfied in the initial solution, and constraints of type 3 must be satisfied over multiple periods. This study investigates a novel method using three stages to solve the problem.

\subsection{Producing a Feasible Solution Space Satisfying Constraint} Types 1 and 2. Mathematically, the MTSFTPP problem, like the UC problem, suffers from the curse of dimensionality as the number of units and the computational period increases. Thus, it is difficult to solve this problem by considering a simple combination of units. For a power grid with five thermal plants, each having four units, the total number of unit combinations will reach $8.67 \times 10^{41}$ for a horizon of one month, and the search will be computationally expensive. Fortunately, the actual constraints on the thermal power load factors and the number of units are beneficial because they reduce the search space when searching for feasible solutions. The specific procedure is as follows.

Step 1. For the thermal plants with different values of unit capacity, each plant will be represented by several "virtual plants" whose capacity depends on the number of units of a given type. For instance, for a thermal plant with 5 units, including 2 units with $300 \mathrm{MW}$ of capacity and 3 units with $200 \mathrm{MW}$ of capacity, the plant will be divided into 2 "virtual plants." By initializing the plants in this manner, the final number of virtual plants will be greater than the number of actual plants and will be denoted as $M$.

Step 2. Start from the first period; that is, let $t=1$.

Step 3. Sort the combinations $U_{t}$ that meet the unit constraints in period $t$; that is, $U_{t}=\left\{u_{t}^{1}, u_{t}^{2}, \ldots, u_{t}^{i}, \ldots, u_{t}^{N_{U t}}\right\}(i=$ $\left.1 \sim N_{U t}\right)$, where $N_{U t}$ is the number of combinations that meet constraint 1 (3) in period $t, u_{t}^{i}=\left(u_{t, 1}^{i}, u_{t, 2}^{i}, \ldots, u_{t, k}^{i}, \ldots, u_{t, M}^{i}\right)$, $u_{k, t}^{\min } \leq u_{k, t}^{i} \leq u_{k, t}^{\max }(k=1 \sim M)$. 


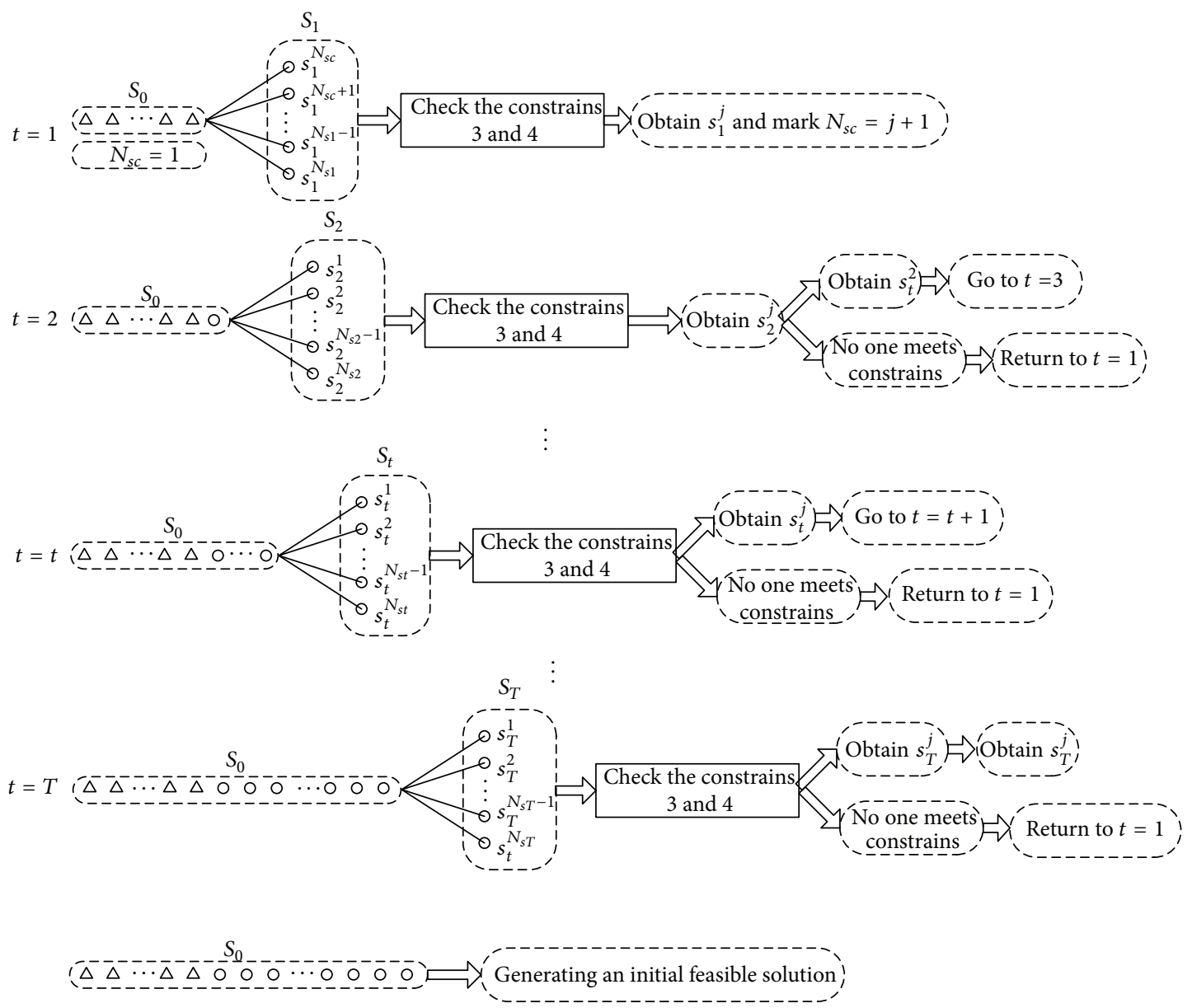

FIgURE 2: The procedure for generating an initial feasible solution.

Step 4. Select the combinations $S_{t}$ that satisfy the thermal power load factor constraints from $U_{t}$ in period $t$; that is, $S_{t}=\left\{s_{t}^{1}, s_{t}^{2}, \ldots, s_{t}^{j}, \ldots, s_{t}^{N_{s t}}\right\}\left(j=1 \sim N_{s t}\right)$, where $N_{s t}$ is the number of combinations that satisfy constraints 1 and 2 ((3) and (4)) in period $t$.

Step 5. If $t<T$, set $t=t+1$ and return to Step 3 . Otherwise, stop and retain the feasible solution space $S=$ $\left\{S_{1}, S_{2}, \ldots, S_{t}, \ldots, S_{T}\right\}$ satisfying constraints 1 and 2 ((3) and (4)).

3.2. Generating an Initial Feasible Solution Using a Heuristic Method. At this point, we have obtained the feasible space satisfying constraints of types 1 and 2 . Finding the optimum in the next stage requires a solution that satisfies all of the operational and system constraints. A heuristic method is proposed for this goal. The procedure is as follows.

Step 1. Obtain the operating data for $d$ days before the starting point. These data will be stored in an array and denoted as the scheme $S_{0}$. The midterm schedule must satisfy the boundary constraints (type 4 ) between actual operation and future scheduling.
Step 2. Start from the first period; that is, let $t=1$.

Step 3. Obtain all combinations $S_{t}$ for period $t(t=1 \sim T)$ using the method described in Section 3.1.

Step 4. Choose a combination that satisfies constraint type 3 in (5) and that is suitable for the boundary constraints, type 4. For each subset $s_{t}^{j}\left(j=1 \sim N_{s t}\right)$ in combination space $S_{t}$ at period $t$, check the type 3 and type 4 constraints. In particular, the type 4 constraints use the historical data $S_{0}$ to satisfy the minimum-time constraints at the starting points. Clearly, $S_{0}$ includes the historical data when $t=1$. The search is stopped and the current subset appended to $S_{0}$ when a feasible subset is found for all subsets $s_{t}^{j}\left(j=1 \sim N_{s t}\right)$. The subset number in the first period is stored to reduce the search in the next cycle. In this case, continue to the next period and set $t=t+$ 1. Otherwise, return to the first period, start from the stored number, and repeat the previous procedure. An initial feasible solution will be generated for the optimization.

A flow chart and pseudocode for generating an initial feasible solution are shown in Figure 2 and Algorithm 1, respectively. 


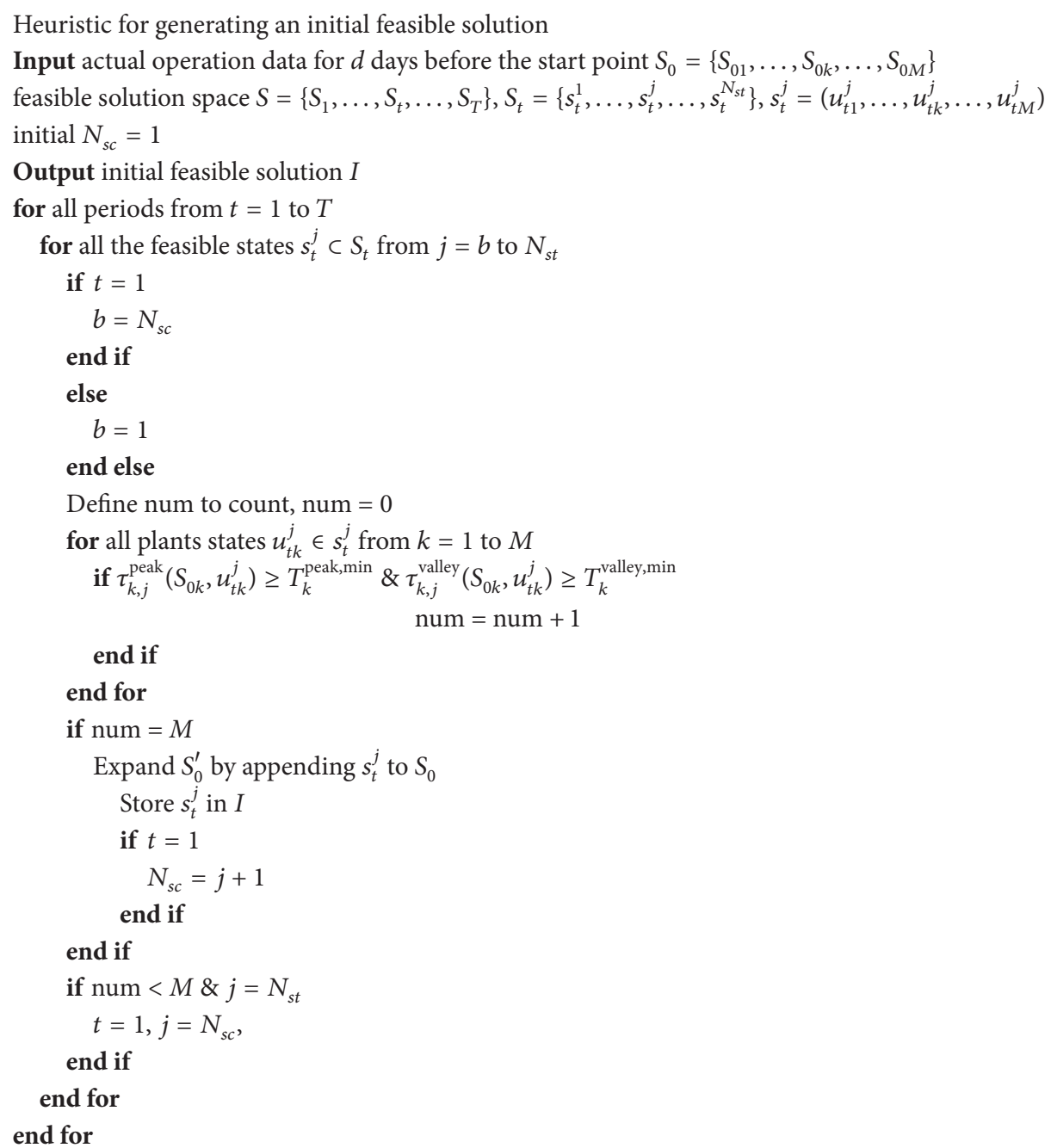

Algorithm 1: Algorithm for generating an initial feasible solution.

3.3. Hybrid Search Algorithm. Numerous operational and system constraints are imposed in the unit commitment problem. The aforementioned initial feasible solution meets only some constraints, and the optimization for unit commitment still must be performed. Sections 3.3.1 and 3.3.2 present a two-step procedure for optimization.

3.3.1. Vertical Search Algorithm. Over the past few decades, the progressive optimality algorithm [28] (POA) has been shown to have great advantages over classical optimization methods and has been one of the most widely used techniques for hydroelectric generator scheduling and water resources problems [29-31]. The POA attempts to find the best solution in a given decision space based on Bellman's Principle and is free of a particular model structure. The advantages of the POA over other optimization techniques are that it can decompose a multistate decision problem into several nonlinear programming subproblems to reduce the dimensionality. In fact, the optimal scheduling of thermal power plants is a multistate and multistage problem, and hence it is suitable for the POA. The POA is defined as follows [27]:

$$
\begin{aligned}
f & =\min \sum_{t=1}^{T} g\left(x_{t-1}, x_{t}\right), \\
G\left(x_{t-1}, x_{t+1}\right) & =\min _{1 \leq j \leq N_{t}}\left[g\left(x_{t-1}, x_{t}^{j}\right)+g\left(x_{t}^{j}, x_{t+1}\right)\right],
\end{aligned}
$$

where $x_{t}^{j}$ is the state $j$ in period $t, G\left(x_{t-1}, x_{t+1}\right)$ is the objective function in period $t$, and $x_{t-1}$ and $x_{t+1}$ are the decision variables in periods $t-1$ and $t+1$, respectively. For the optimal scheduling of thermal power plants, the problem can be mathematically stated as follows:

$$
\begin{aligned}
f & =\min D(H), \\
G\left(s_{t}, s_{t+1}\right) & =\min _{1 \leq j \leq N_{s t}}\left[D\left(H\left(s_{t}^{j}, s_{t+1}\right)\right)\right] \quad 1 \leq t<T, \\
G\left(s_{t-1}, s_{t}\right) & =\min _{1 \leq j \leq N_{s t}}\left[D\left(H\left(s_{t-1}, s_{t}^{j}\right)\right)\right] \quad t=T,
\end{aligned}
$$




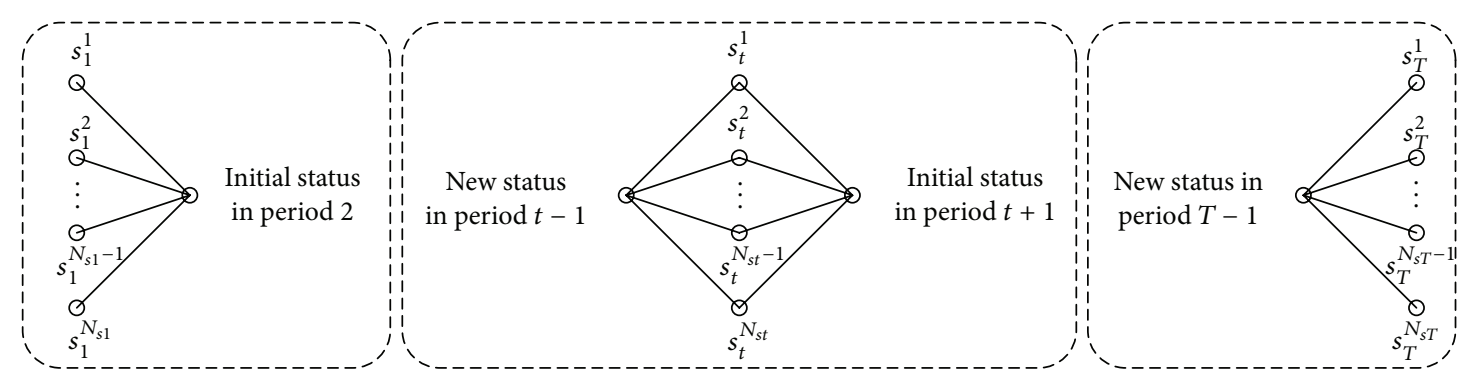

FIgURE 3: Search principle of VSA using POA.

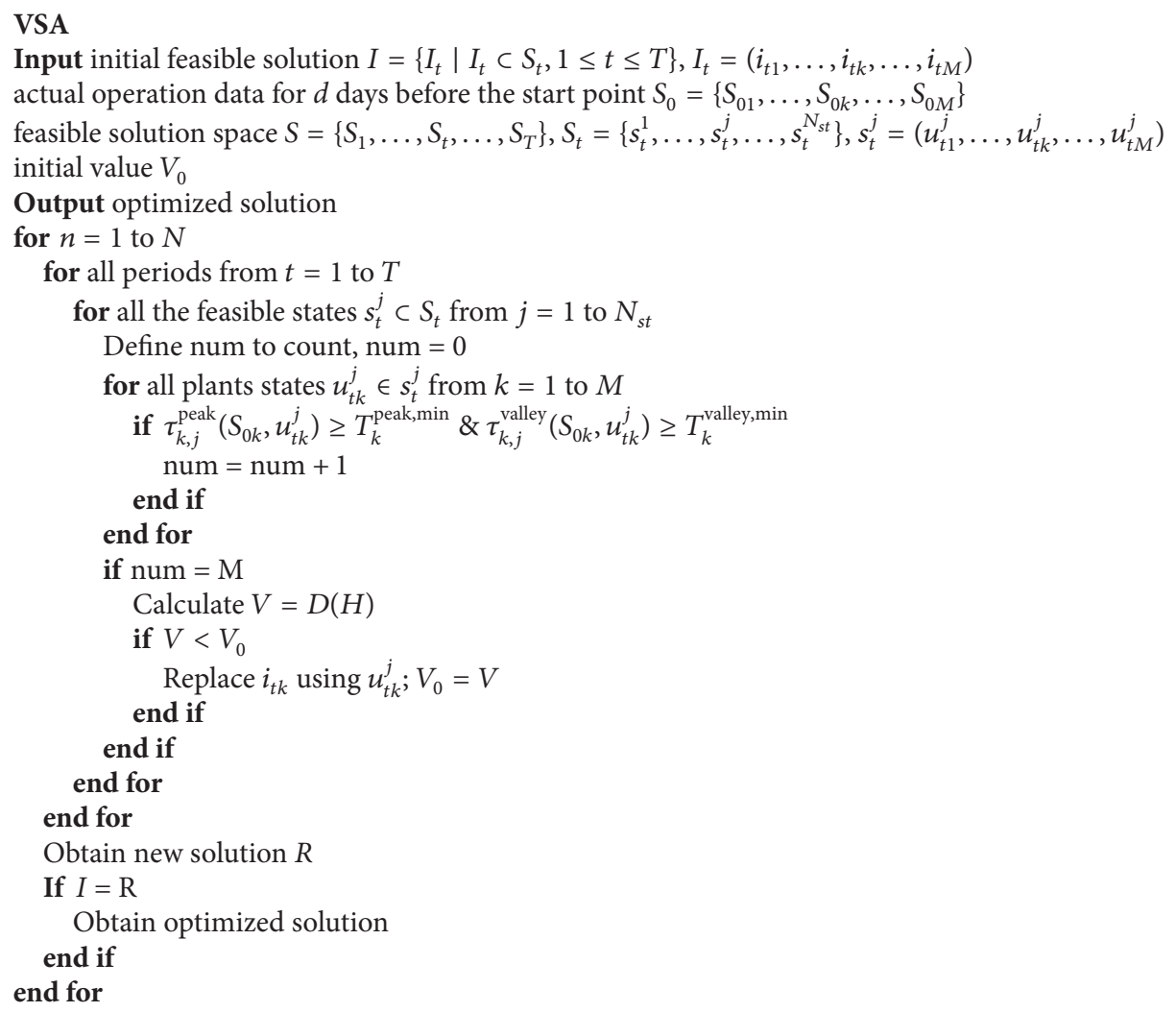

Algorithm 2: Algorithm for VSA.

where $H\left(s_{t}^{j}, s_{t+1}\right)$ and $H\left(s_{t-1}, s_{t}^{j}\right)$ are functions that give the operating hours of installed capacity when the status is $s_{t}^{j}$ and $G\left(s_{t}, s_{t+1}\right)$ and $G\left(s_{t-1}, s_{t}\right)$ are the objective functions for period $t$. With this formulation, we choose $s_{t}^{j}$ from $S_{t}$ with the status in the other periods fixed to obtain the optimal objective function value. A diagram of the operating of the POA is shown in Figure 3, and pseudocode for the algorithm is shown in Algorithm 2.

The aforementioned search is a sequential procedure, which we refer to as the vertical search algorithm (VSA), as distinguished from the following search algorithm.

3.3.2. Lateral Search Algorithm. The solution obtained using the VSA is clearly affected by the starting point (i.e., initial guess) and can converge to a local minimum. Hence, another search strategy is presented to improve the solution by enlarging the search space. The search addresses the objective that all plants have equal or approximately equal operating hours of installed capacity. To attain this goal, the plants whose operating hours are greater than or less than the average value will be adjusted. The plant with the greatest bias from the average is selected for adjustment. Generally, we choose the periods of maximum or minimum plant output to perform the adjustments. This state involves situations in which the system load allows for a change in the number of active units. Another state occurs in periods of maximum or minimum output during which a change in the number of active units in other periods is not possible. For the first case, the adjustment is started from the first period among the periods 


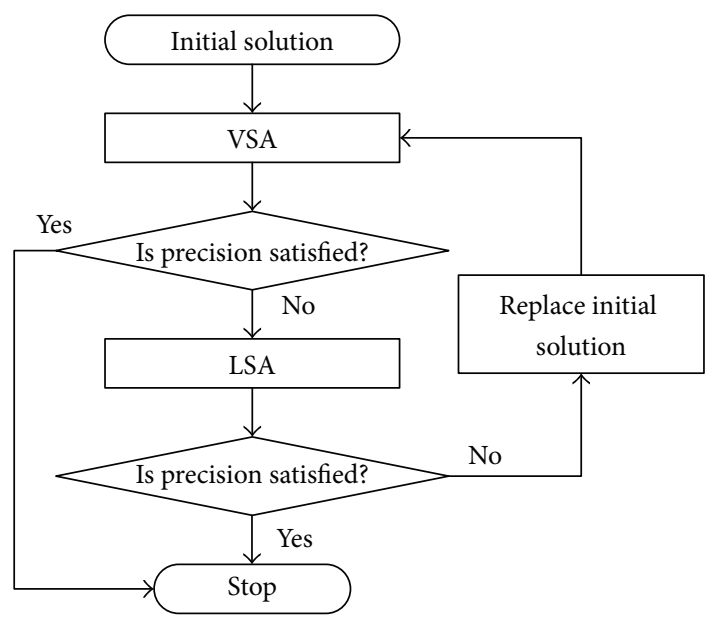

FIGURE 4: Search procedure for HSA using VSA and LSA.

of maximum or minimum output. The increase or decrease in the number of units depends on the difference from the average and the constraints. If the plant's operating hours of installed capacity are greater than the average, we decrease the number of units for selected periods. This adjustment is a trial procedure because of the complex constraints and because the starting period for the adjustment is related to the constraints. For the second case, the changes in the maximum/minimum output periods will cause a change in the unit status in subsequent periods due to the minimum-time constraints. The adjustment features two aspects: satisfying all of the constraints in the maximum- or minimum-output periods and satisfying the constraints in subsequent periods. In either case, a new feasible solution will be produced. Consequently, an updated optimal solution can be obtained using the VSA. Herein, we refer to the search procedure as the lateral search algorithm (LSA). An optimal solution that satisfies the constraints can be obtained using the VSA and LSA alternately. A flowchart for the hybrid search algorithm that combines the VSA and LSA is shown in Figure 4.

\section{Case Study}

The proposed method was applied to the MTSFTPP problem for an actual power system, the Yunnan Power Grid (YPG) in China. Currently, it is used as the primary tool to determine the midterm optimal scheduling of thermal power plants by the operators of YPG. Yunnan is among the richest in hydropower resources of all of the provinces in China. Its potential hydropower capacity is $103.6 \mathrm{GW}$, which contributes $15.3 \%$ of the national capacity and ranks third in the nation. The exploitable hydropower capacity is $90 \mathrm{GW}$, which contributes $17.9 \%$ and ranks second in the nation. By the end of 2013, the total installed capacity of the YPG had reached $26.1 \mathrm{GW}$, with hydropower capacity accounting for $16.7 \mathrm{GW}$ and thermal capacity accounting for $8.935 \mathrm{GW}$. Proper scheduling of thermal power plants can make the best use of hydropower systems and improve system security.
TABLE 1: Thermal power system in the YPG.

\begin{tabular}{lcc}
\hline Plant number & $\begin{array}{c}\text { Units } \\
\text { (number } * \text { capacity, MW) }\end{array}$ & Capacity (MW) \\
\hline 1 & $4 * 600$ & 2400 \\
2 & $6 * 300$ & 1800 \\
3 & $4 * 300$ & 1200 \\
4 & $2 * 200+2 * 300$ & 1000 \\
5 & $2 * 300$ & 600 \\
6 & $2 * 300$ & 600 \\
7 & $2 * 300$ & 600 \\
8 & $2 * 300$ & 600 \\
9 & $1 * 135$ & 135 \\
\hline
\end{tabular}

The thermal power system in the YPG consists of 9 thermal power plants with a total installed capacity of $8.935 \mathrm{GW}$ and 27 units. The dispatching center in the YPG controls the thermal power system. Table 1 lists the basic data for these plants. The HSA was implemented in Java and executed on a PC with an Intel Core 2 Duo $2.93 \mathrm{GHz}$ CPU and $2 \mathrm{~GB}$ of memory. An actual schedule for 2013 in the YPG was used to test the validity and the computational efficiency of the proposed method.

Two typical months, May and September, were selected to demonstrate the practicality and the efficiency of the method. May represents the beginning of the flood season, when the hydropower plants can operate at their peak and the demand on the thermal system can be decreased. Conversely, September represents the beginning of the dry season, when the hydropower system has the lowest output and the demand on the thermal system increases.

According to the real-world operating experience and users' actual demands, the basic parameters for the HSA are set as follows:

(i) minimum load factor $r^{\mathrm{min}}=0.7$;

(ii) maximum load factor $r^{\max }=0.9$;

(iii) initial load factor $r=0.8$;

(iv) actual operating hours of installed capacity in the warm-up period $H_{k p}=0(k=1 \sim 9)$;

(v) extra hours $H_{k e}=0(k=1 \sim 9)$;

(vi) minimum number of units $u_{k t}^{\min }=1(k=1 \sim 8$, $t=1 \sim T$ ), and $u_{k t}^{\min }=0$ for $k=9$;

(vii) maximum number of units $u_{k, t}^{\max }=U A_{k, t}^{\max }(k=1 \sim 9$, $t=1 \sim T$ ), where $U A_{k, t}^{\max }$ is the number of available units for plant $k$ in period $t$;

(viii) minimum duration of peak in plant output $T_{k}^{\text {peak,min }}=$ 7 days $(k=1 \sim 9)$;

(ix) minimum duration of valley in plant output $T_{k}^{\text {valley,min }}=3$ days $(k=1 \sim 9)$;

(x) considering previous periods $d_{k}=7$ days $(k=1 \sim 9)$.

The average cost time of 10 runs for May is $9764 \mathrm{~ms}$ and for September is $10241 \mathrm{~ms}$, and the calculation efficiency can be met the actual demand in midterm scheduling. 
TABLE 2: Comparison of three methods for two typical months.

\begin{tabular}{|c|c|c|c|c|c|c|c|c|}
\hline & \multicolumn{4}{|c|}{ May } & \multicolumn{4}{|c|}{ September } \\
\hline & Heuristic & VSA & LSA & HSA & Heuristic & VSA & LSA & HSA \\
\hline \multicolumn{9}{|c|}{ Operating hours of installed capacity (h) } \\
\hline Plant 1 & 475.2 & 484.8 & 499.2 & 499.2 & 264 & 288 & 288 & 288 \\
\hline Plant 2 & 499.2 & 499.2 & 499.2 & 499.2 & 304 & 284.8 & 284.8 & 288 \\
\hline Plant 3 & 475.2 & 499.2 & 499.2 & 499.2 & 244.8 & 278.4 & 292.8 & 288 \\
\hline Plant 4 & 499.2 & 499.2 & 499.2 & 499.2 & 268.8 & 282.2 & 282.2 & 288 \\
\hline Plant 5 & 489.6 & 499.2 & 499.2 & 499.2 & 288 & 288 & 288 & 288 \\
\hline Plant 6 & 499.2 & 499.2 & 499.2 & 499.2 & 288 & 288 & 288 & 288 \\
\hline Plant 7 & 499.2 & 499.2 & 499.2 & 499.2 & 288 & 288 & 288 & 288 \\
\hline Plant 8 & 489.6 & 499.2 & 499.2 & 499.2 & 288 & 288 & 288 & 288 \\
\hline Plant 9 & 480 & 480 & 480 & 499.2 & 268.8 & 288 & 288 & 288 \\
\hline Average (h) & 489.6 & 495.5 & 497.1 & 499.2 & 278.04 & 285.9 & 287.5 & 288 \\
\hline Max-min difference (h) & 24 & 19.2 & 19.2 & 0 & 59.2 & 9.6 & 10.6 & 0 \\
\hline Objective value (h2) & 97.28 & 50.06 & 36.4 & 0 & 282.61 & 10.81 & 7.17 & 0 \\
\hline
\end{tabular}

In a comparison of the results obtained by the HSA with those obtained by the heuristic, the VSA and the LSA are shown in Table 2. As indicated by the table, the results improve progressively in going from the heuristic to the HSA for most of the evaluation criteria, including the average, the max-min difference, and the objective value, for both May and September. It should be noted that the most improved solutions were achieved by the VSA, which demonstrated that the VSA has the capability to find the optimal solution. The LSA attempts to improve the objective function value and avoid convergence to a local minimum. As shown in Table 2, Plant 1 was changed in May by the LSA. Although the maxmin difference remained the same, the objective function was diminished from 50.06 to 36.4 . There is little difference in the results obtained between September and May. Due to the adjustments to the generating units in the valley periods by the LSA, the max-min difference was greater, but the objective function decreased from 10.81 to 7.17. Equal values for all three evaluation criteria were attained for May and September using the HSA, which indicates that the HSA has the capability to find the global minimum.

The generation requirements for the 9 plants in May are shown in Figure 5 and the details of results are listed in Table 3. Meanwhile, the generation requirements and details in September are shown in Figure 6 and Table 4. From Tables 3 and 4, it can be seen that the boot capacity result of each plant can meet all constraints. In Plant 2 in Table 3, for example, the days of first peak in plant output are 8 (from 7 th to 14 th) which is bigger than minimum duration of peak in plant output $T_{k}^{\text {peak,min }}=7$ days, while the days of first valley in plant output are 4 (from 17th to 20th) which is bigger than minimum duration of valley in plant output $T_{k}^{\text {valley,min }}=3$ days. Figure 5 shows that the outputs of most of the plants by the end of May were reduced to take advantage of the hydropower system. Plant 4 appears to have been an exception to this trend in May and could not satisfy the peak time constraint by the end of May, but this result is misleading. Table 1 shows that Plant 4 has two types of turbine units, 2 units of $200 \mathrm{MW}$ capacity and 2 units of $300 \mathrm{MW}$ capacity. As described in Section 3.1, Plant 4 was divided into two "virtual plants" for computational purposes. Table 3 and Figure 7 show the generation requirements for "virtual plants" 1 and 2 and demonstrate that these plants exhibit the same performance as the other plants. Conversely, the outputs of all of the plants increased from the beginning of September. Figures 5 and 6 demonstrate that the MTSFTPP results for May and September are reasonable.

Figures 8 and 9 show the generation and capacity requirements in May and September, respectively. It can be observed that the generation requirements are between maximum and minimum capacity.

\section{Conclusions}

A model for the MTSFTPP problem was proposed. The model includes three stages. The feasible spaces for the MTSFTPP problem are first produced by narrowing the search space based on constraints 1 and 2. Next, an initial feasible solution for the MTSFTPP problem is obtained using virtual plants and considering constraints 3 and 4 . The POA is used to solve the MTSFTPP problem, and the optimal search is referred to as the VSA. To avoid convergence to a local minimum, the LSA is used, and the updated solution is used as a new feasible starting point for the next search with the VSA. Thus, the HSA is produced by combining the LSA with the VSA. A complete framework for solving the MTSFTPP problem was established and demonstrated using a case study. The results showed that the proposed method can efficiently produce satisfactory solutions with practical requirements. 

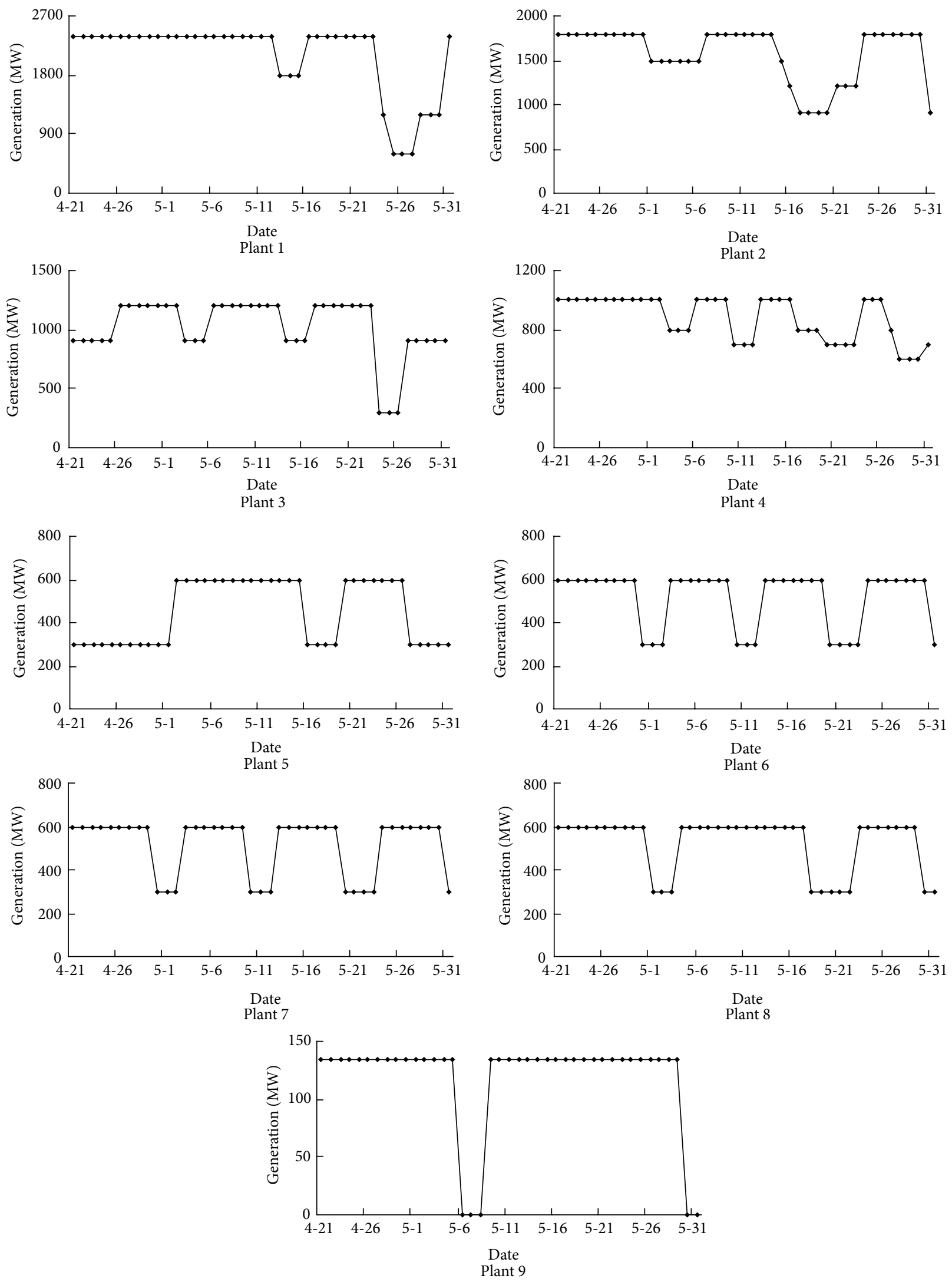

Figure 5: The process of generation requirements for Plants 1 to 9 in May. 

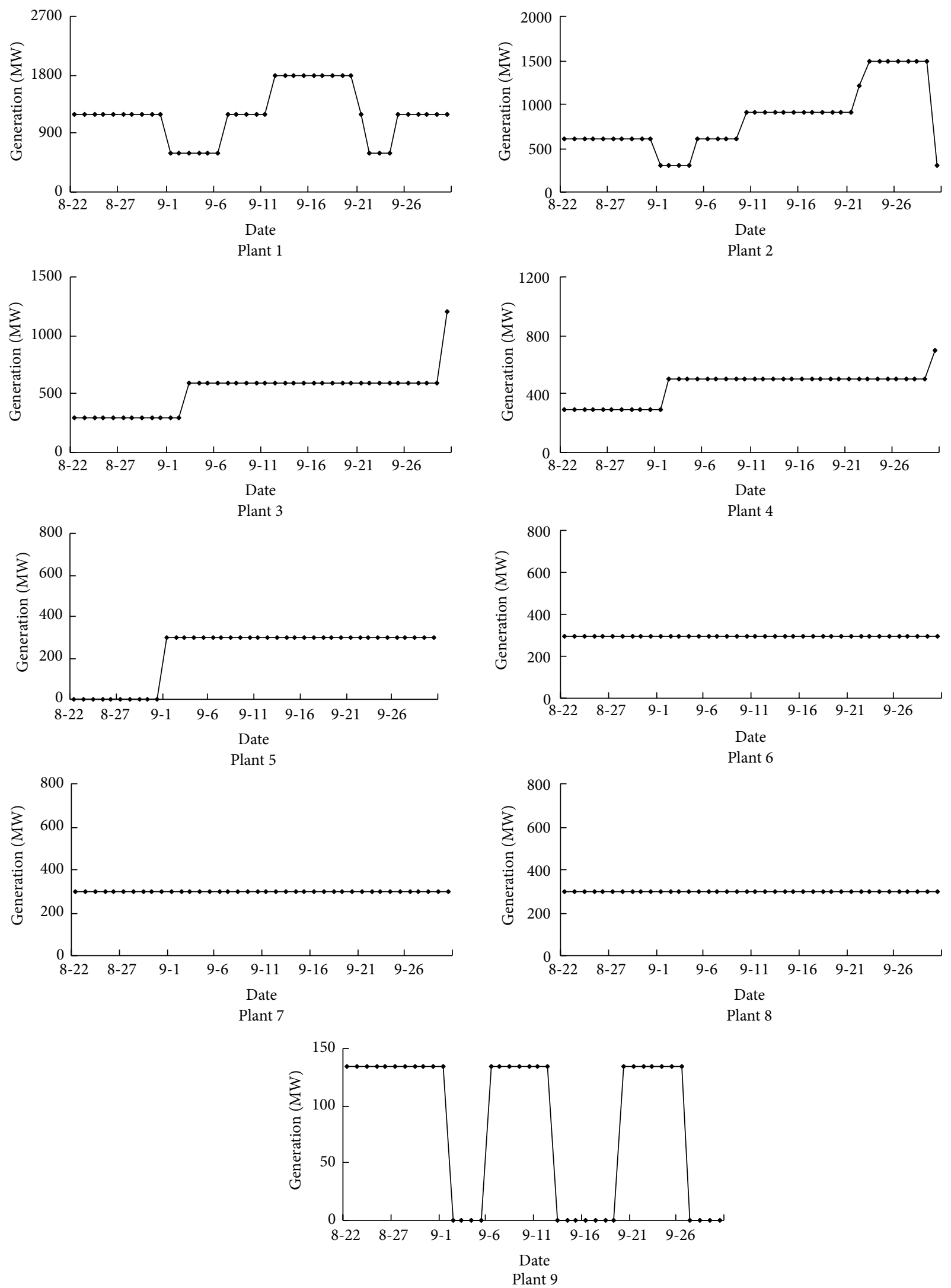

FIgURE 6: The process of generation requirements for Plants 1 to 9 in September. 
TABLE 3: Results of generation requirements for Plants 1 to 9 in May (MW).

\begin{tabular}{|c|c|c|c|c|c|c|c|c|c|c|c|}
\hline \multirow{2}{*}{ Date } & \multirow{2}{*}{ Plant 1} & \multirow{2}{*}{ Plant 2} & \multirow{2}{*}{ Plant 3} & \multicolumn{3}{|c|}{ Plant 4} & \multirow{2}{*}{ Plant 5} & \multirow{2}{*}{ Plant 6} & \multirow{2}{*}{ Plant 7} & \multirow{2}{*}{ Plant 8} & \multirow{2}{*}{ Plant $S$} \\
\hline & & & & Virtual plant 1 & Virtual plant 2 & Total & & & & & \\
\hline 1st & 2400 & 1500 & 1200 & 400 & 600 & 1000 & 300 & 300 & 300 & 300 & 135 \\
\hline 2nd & 2400 & 1500 & 1200 & 400 & 600 & 1000 & 600 & 300 & 300 & 300 & 135 \\
\hline $3 \mathrm{rd}$ & 2400 & 1500 & 900 & 200 & 600 & 800 & 600 & 600 & 600 & 300 & 135 \\
\hline 4 th & 2400 & 1500 & 900 & 200 & 600 & 800 & 600 & 600 & 600 & 600 & 135 \\
\hline 5 th & 2400 & 1500 & 900 & 200 & 600 & 800 & 600 & 600 & 600 & 600 & 135 \\
\hline 6 th & 2400 & 1500 & 1200 & 400 & 600 & 1000 & 600 & 600 & 600 & 600 & 0 \\
\hline 7 th & 2400 & 1800 & 1200 & 400 & 600 & 1000 & 600 & 600 & 600 & 600 & 0 \\
\hline 8 th & 2400 & 1800 & 1200 & 400 & 600 & 1000 & 600 & 600 & 600 & 600 & 0 \\
\hline 9 th & 2400 & 1800 & 1200 & 400 & 600 & 1000 & 600 & 600 & 600 & 600 & 135 \\
\hline 10th & 2400 & 1800 & 1200 & 400 & 300 & 700 & 600 & 300 & 300 & 600 & 135 \\
\hline 11th & 2400 & 1800 & 1200 & 400 & 300 & 700 & 600 & 300 & 300 & 600 & 135 \\
\hline 12 th & 2400 & 1800 & 1200 & 400 & 300 & 700 & 600 & 300 & 300 & 600 & 135 \\
\hline 13th & 1800 & 1800 & 1200 & 400 & 600 & 1000 & 600 & 600 & 600 & 600 & 135 \\
\hline 14th & 1800 & 1800 & 900 & 400 & 600 & 1000 & 600 & 600 & 600 & 600 & 135 \\
\hline 15th & 1800 & 1500 & 900 & 400 & 600 & 1000 & 600 & 600 & 600 & 600 & 135 \\
\hline 16th & 2400 & 1200 & 900 & 400 & 600 & 1000 & 300 & 600 & 600 & 600 & 135 \\
\hline 17 th & 2400 & 900 & 1200 & 200 & 600 & 800 & 300 & 600 & 600 & 600 & 135 \\
\hline 18th & 2400 & 900 & 1200 & 200 & 600 & 800 & 300 & 600 & 600 & 300 & 135 \\
\hline 19th & 2400 & 900 & 1200 & 200 & 600 & 800 & 300 & 600 & 600 & 300 & 135 \\
\hline 20th & 2400 & 900 & 1200 & 400 & 300 & 700 & 600 & 300 & 300 & 300 & 135 \\
\hline 21 st & 2400 & 1200 & 1200 & 400 & 300 & 700 & 600 & 300 & 300 & 300 & 135 \\
\hline 22nd & 2400 & 1200 & 1200 & 400 & 300 & 700 & 600 & 300 & 300 & 300 & 135 \\
\hline $23 \mathrm{rd}$ & 2400 & 1200 & 1200 & 400 & 300 & 700 & 600 & 300 & 300 & 600 & 135 \\
\hline 24th & 1200 & 1800 & 300 & 400 & 600 & 1000 & 600 & 600 & 600 & 600 & 135 \\
\hline 25th & 600 & 1800 & 300 & 400 & 600 & 1000 & 600 & 600 & 600 & 600 & 135 \\
\hline 26th & 600 & 1800 & 300 & 400 & 600 & 1000 & 600 & 600 & 600 & 600 & 135 \\
\hline 27th & 600 & 1800 & 900 & 200 & 600 & 800 & 300 & 600 & 600 & 600 & 135 \\
\hline 28th & 1200 & 1800 & 900 & 0 & 600 & 600 & 300 & 600 & 600 & 600 & 135 \\
\hline 29th & 1200 & 1800 & 900 & 0 & 600 & 600 & 300 & 600 & 600 & 600 & 135 \\
\hline 30th & 1200 & 1800 & 900 & 0 & 600 & 600 & 300 & 600 & 600 & 300 & 0 \\
\hline 31st & 2400 & 900 & 900 & 400 & 300 & 700 & 300 & 300 & 300 & 300 & 0 \\
\hline
\end{tabular}
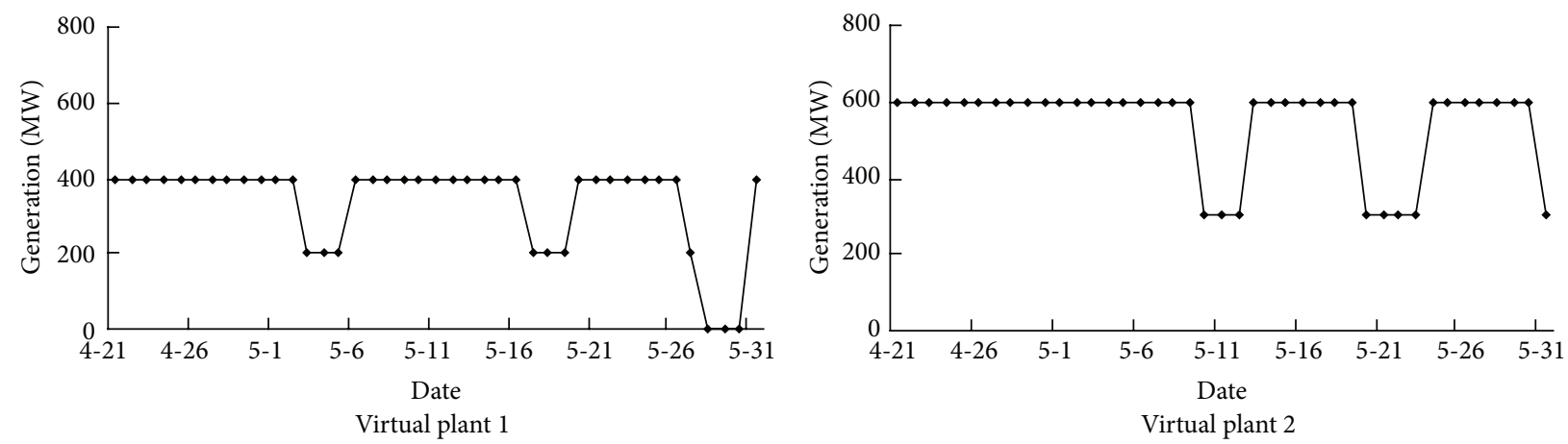

FIgURE 7: The process of generation requirements for "virtual plants" 1 and 2. 
TABLE 4: Results of generation requirements for Plants 1 to 9 in September.

\begin{tabular}{|c|c|c|c|c|c|c|c|c|c|}
\hline Date & Plant 1 & Plant 2 & Plant 3 & Plant 4 & Plant 5 & Plant 6 & Plant 7 & Plant 8 & Plant 9 \\
\hline 1st & 600 & 300 & 300 & 300 & 300 & 300 & 300 & 300 & 135 \\
\hline 2nd & 600 & 300 & 300 & 600 & 300 & 300 & 300 & 300 & 0 \\
\hline $3 r d$ & 600 & 300 & 600 & 600 & 300 & 300 & 300 & 300 & 0 \\
\hline 4 th & 600 & 300 & 600 & 600 & 300 & 300 & 300 & 300 & 0 \\
\hline 5 th & 600 & 600 & 600 & 600 & 300 & 300 & 300 & 300 & 0 \\
\hline 6 th & 600 & 600 & 600 & 600 & 300 & 300 & 300 & 300 & 135 \\
\hline 7th & 1200 & 600 & 600 & 600 & 300 & 300 & 300 & 300 & 135 \\
\hline 8th & 1200 & 600 & 600 & 600 & 300 & 300 & 300 & 300 & 135 \\
\hline 9th & 1200 & 600 & 600 & 600 & 300 & 300 & 300 & 300 & 135 \\
\hline 10th & 1200 & 900 & 600 & 600 & 300 & 300 & 300 & 300 & 135 \\
\hline 11th & 1200 & 900 & 600 & 600 & 300 & 300 & 300 & 300 & 135 \\
\hline 12 th & 1800 & 900 & 600 & 600 & 300 & 300 & 300 & 300 & 135 \\
\hline 13th & 1800 & 900 & 600 & 600 & 300 & 300 & 300 & 300 & 0 \\
\hline 14th & 1800 & 900 & 600 & 600 & 300 & 300 & 300 & 300 & 0 \\
\hline 15 th & 1800 & 900 & 600 & 600 & 300 & 300 & 300 & 300 & 0 \\
\hline 16 th & 1800 & 900 & 600 & 600 & 300 & 300 & 300 & 300 & 0 \\
\hline 17th & 1800 & 900 & 600 & 600 & 300 & 300 & 300 & 300 & 0 \\
\hline 18th & 1800 & 900 & 600 & 600 & 300 & 300 & 300 & 300 & 0 \\
\hline 19th & 1800 & 900 & 600 & 600 & 300 & 300 & 300 & 300 & 0 \\
\hline 20th & 1800 & 900 & 600 & 600 & 300 & 300 & 300 & 300 & 135 \\
\hline 21st & 1200 & 900 & 600 & 600 & 300 & 300 & 300 & 300 & 135 \\
\hline $22 \mathrm{nd}$ & 600 & 1200 & 600 & 600 & 300 & 300 & 300 & 300 & 135 \\
\hline $23 \mathrm{rd}$ & 600 & 1500 & 600 & 600 & 300 & 300 & 300 & 300 & 135 \\
\hline 24 th & 600 & 1500 & 600 & 600 & 300 & 300 & 300 & 300 & 135 \\
\hline 25 th & 1200 & 1500 & 600 & 600 & 300 & 300 & 300 & 300 & 135 \\
\hline 26 th & 1200 & 1500 & 600 & 600 & 300 & 300 & 300 & 300 & 135 \\
\hline 27 th & 1200 & 1500 & 600 & 600 & 300 & 300 & 300 & 300 & 0 \\
\hline 28th & 1200 & 1500 & 600 & 600 & 300 & 300 & 300 & 300 & 0 \\
\hline 29th & 1200 & 1500 & 600 & 600 & 300 & 300 & 300 & 300 & 0 \\
\hline 30th & 1200 & 300 & 1200 & 900 & 300 & 300 & 300 & 300 & 0 \\
\hline
\end{tabular}

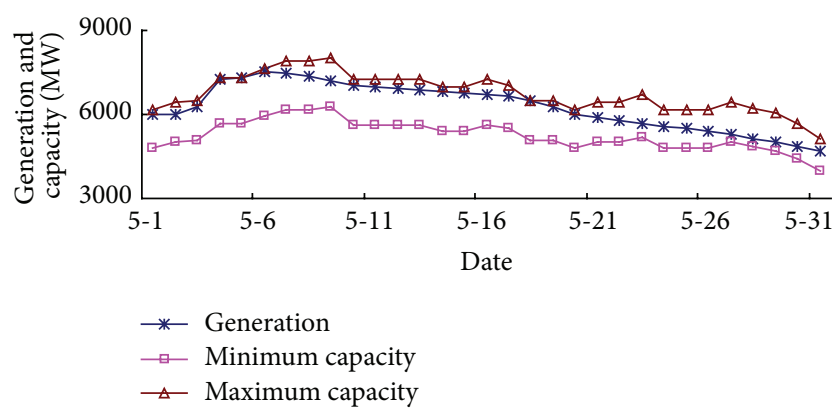

FIGURE 8: Generation and capacity requirements in May.

A novel method focusing on solving strategies for the MTSFTPP problem was proposed, in which the thermal system load was given after the other electric sources were optimized. However, the joint modeling of thermal power system with other source systems in midterm schedule can be considered as a research basis for future studies.

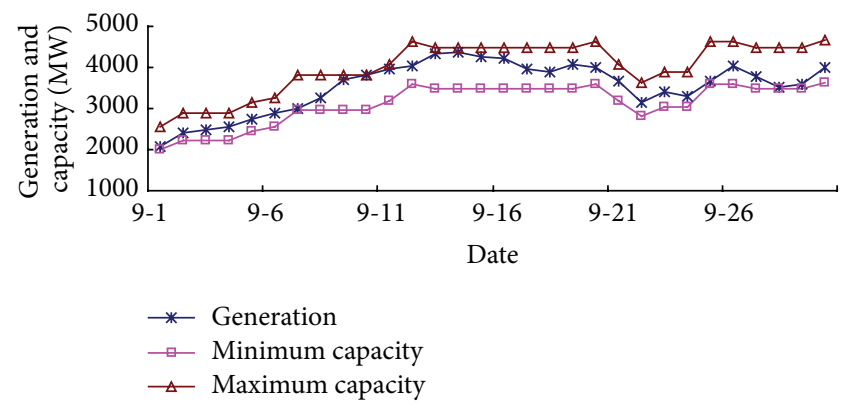

FIGURE 9: Generation and capacity requirements in September.

\section{Conflict of Interests}

The authors declare that there is no conflict of interests regarding the publication of this paper. 


\section{Acknowledgments}

This study is supported by the Major International Joint Research Project (no. 51210014), the National Natural Science Foundation of China (no. 51209029), and the Fundamental Research Funds for the Central Universities (no. DUT14QY15).

\section{References}

[1] China Electric Power Yearbook Editorial Board, China Electric Power Yearbook, China Electric Power Press, 2003-2013.

[2] National Electric Power Industry Statistics Express, 2014, http:// www.sxcoal.com/dl/3636879/articlenew.html.

[3] L. Liu, H. Zong, E. Zhao, C. Chen, and J. Wang, "Can China realize its carbon emission reduction goal in 2020: from the perspective of thermal power development," Applied Energy, vol. 124, pp. 199-212, 2014.

[4] N. P. Padhy, "Unit commitment-a bibliographical survey," IEEE Transactions on Power Systems, vol. 19, no. 2, pp. 1196-1205, 2004.

[5] T. Niknam, A. Khodaei, and F. Fallahi, "A new decomposition approach for the thermal unit commitment problem," Applied Energy, vol. 86, no. 9, pp. 1667-1674, 2009.

[6] S. K. Tong, S. M. Shahidehpour, and Z. Ouyang, "A heuristic short-term unit commitment," IEEE Transactions on Power Systems, vol. 6, no. 3, pp. 1210-1216, 1991.

[7] T. Senjyu, K. Shimabukuro, K. Uezato, and T. Funabashi, "A fast technique for unit commitment problem by extended priority list," IEEE Transactions on Power Systems, vol. 18, no. 2, pp. 882888, 2003.

[8] A. Viana, J. P. de Sousa, and M. A. Matos, "Fast solutions for UC problems by a new metaheuristic approach," Electric Power Systems Research, vol. 78, no. 8, pp. 1385-1395, 2008.

[9] S. Subramanian and S. Ganesan, "A novel hybrid approach using modified priority list and sequential approach for unit commitment," International Journal of Energy Sector Management, vol. 4, no. 4, pp. 555-576, 2010.

[10] C. T. Cheng, S. S. Li, and G. A. Li, "A hybrid method of incorporating extended priority list into equal incremental principle for energy-saving generation dispatch of thermal power systems," Energy, vol. 64, pp. 688-696, 2014.

[11] W. J. Hobbs, G. Hermon, S. Warner, and G. B. Shelbe, "An enhanced dynamic programming approach for unit commitment," IEEE Transactions on Power Systems, vol. 3, no. 3, pp. 1201-1205, 1988.

[12] A. Rong, H. Hakonen, and R. Lahdelma, "A variant of the dynamic programming algorithm for unit commitment of combined heat and power systems," European Journal of Operational Research, vol. 190, no. 3, pp. 741-755, 2008.

[13] W. L. Peterson and S. R. Brammer, "Capacity based Lagrangian relaxation unit commitment with ramp rate constraints," IEEE Transactions on Power Systems, vol. 10, no. 2, pp. 1077-1084, 1995.

[14] Q. Z. Zhai, X. H. Guan, and J. Cui, "Unit commitment with identical units: successive subproblem solving method based on Lagrangian relaxation," IEEE Transactions on Power Systems, vol. 17, no. 4, pp. 1250-1257, 2002.

[15] T. Seki, N. Yamashita, and K. Kawamoto, "New local search methods for improving the lagrangian-relaxation-based unit commitment solution," IEEE Transactions on Power Systems, vol. 25, no. 1, pp. 272-283, 2010.

[16] A. Grey and A. Sekar, "Unified solution of security-constrained unit commitment problem using a linear programming methodology," IET Generation, Transmission \& Distribution, vol. 2, no. 6, pp. 856-867, 2008.

[17] B. Venkatesh, T. Jamtsho, and H. B. Gooi, "Unit commitmenta fuzzy mixed integer linear programming solution," IET Generation, Transmission and Distribution, vol. 1, no. 5, pp. 836-846, 2007.

[18] N. Amjady and A. Shirzadi, "Unit commitment using a new integer coded genetic algorithm," European Transactions on Electrical Power, vol. 19, no. 8, pp. 1161-1176, 2009.

[19] B. Yu, Z. Z. Yang, X. S. Sun, B. Yao, Q. Zeng, and E. Jeppesen, "Parallel genetic algorithm in bus route headway optimization," Applied Soft Computing Journal, vol. 11, no. 8, pp. 5081-5091, 2011.

[20] C. Y. Dang and M. Q. Li, "A floating-point genetic algorithm for solving the unit commitment problem," European Journal of Operational Research, vol. 181, no. 3, pp. 1370-1395, 2007.

[21] G. Dudek, "Genetic algorithm with integer representation of unit start-up and shut-down times for the unit commitment problem," European Transactions on Electrical Power, vol. 17, no. 5, pp. 500-511, 2007.

[22] V. Senthil Kumar and M. R. Mohan, "Solution to security constrained unit commitment problem using genetic algorithm," International Journal of Electrical Power and Energy Systems, vol. 32, no. 2, pp. 117-125, 2010.

[23] C. T. Cheng, C. P. Ou, and K. W. Chau, "Combining a fuzzy optimal model with a genetic algorithm to solve multi-objective rainfall-runoff model calibration," Journal of Hydrology, vol. 268, no. 1-4, pp. 72-86, 2002.

[24] C.-T. Cheng, W.-C. Wang, D.-M. Xu, and K. W. Chau, "Optimizing hydropower reservoir operation using hybrid genetic algorithm and chaos," Water Resources Management, vol. 22, no. 7, pp. 895-909, 2008.

[25] M. P. Walsh and M. J. O’Malley, "Augmented hopfield network for unit commitment and economic dispatch," IEEE Transactions on Power Systems, vol. 12, no. 4, pp. 1765-1774, 1997.

[26] M. H. Wong, T. S. Chung, and Y. K. Wong, "Evolving neural network approach in unit commitment solution," Microprocessors and Microsystems, vol. 24, no. 5, pp. 251-262, 2000.

[27] J.-X. Xie, C.-T. Cheng, K.-W. Chau, and Y.-Z. Pei, "A hybrid adaptive time-delay neural network model for multi-stepahead prediction of sunspot activity," International Journal of Environment and Pollution, vol. 28, no. 3-4, pp. 364-381, 2006.

[28] H. R. Howson and N. G. Sancho, "A new algorithm for the solution of multi-state dynamic programming problems," Mathematical Programming, vol. 8, pp. 104-116, 1975.

[29] A. Turgeon, "Optimal short-term hydro scheduling from the principle of progressive optimality," Water Resources Research, vol. 17, no. 3, pp. 481-486, 1981.

[30] N. J. D. Lucas and P. J. Perera, "Short-term hydroelectric scheduling using the progressive optimality algorithm," Water Resources Research, vol. 21, no. 9, pp. 1456-1458, 1985.

[31] J. Nanda, P. R. Bijwe, and D. P. Kothari, "Application of progressive optimality algorithm to optimal hydrothermal scheduling considering deterministic and stochastic data," International Journal of Electrical Power and Energy Systems, vol. 8, no. 1, pp. 61-64, 1986. 


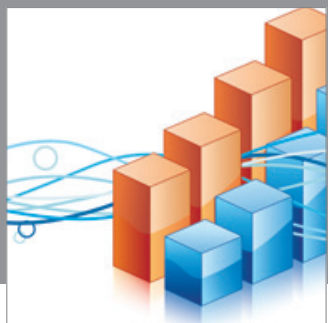

Advances in

Operations Research

mansans

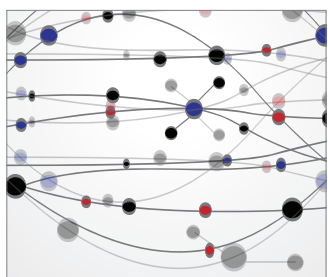

The Scientific World Journal
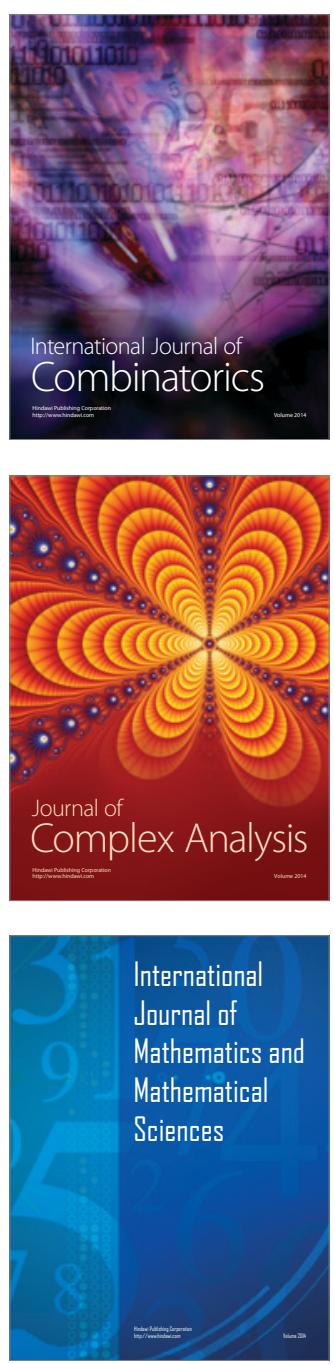
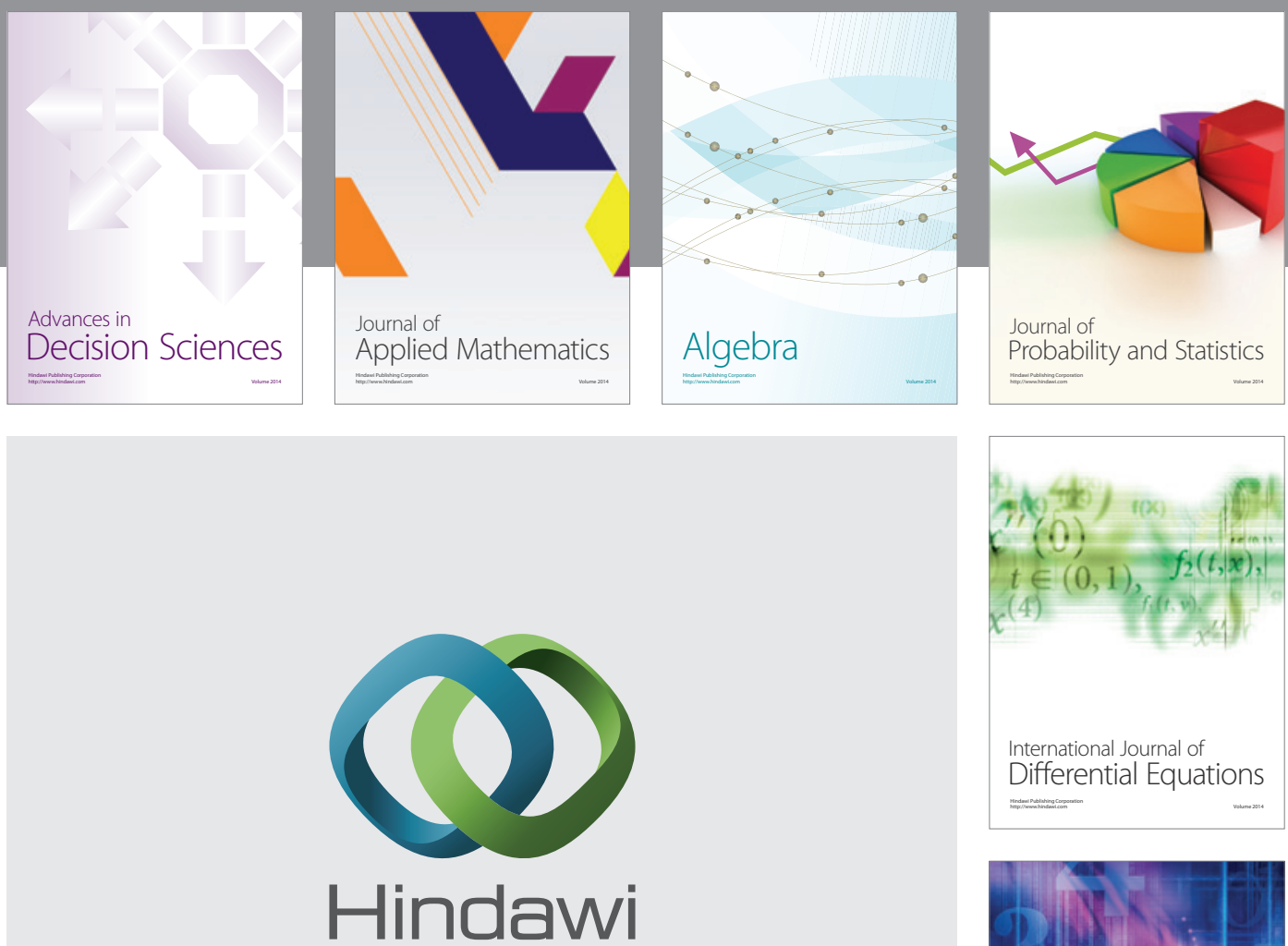

Submit your manuscripts at http://www.hindawi.com
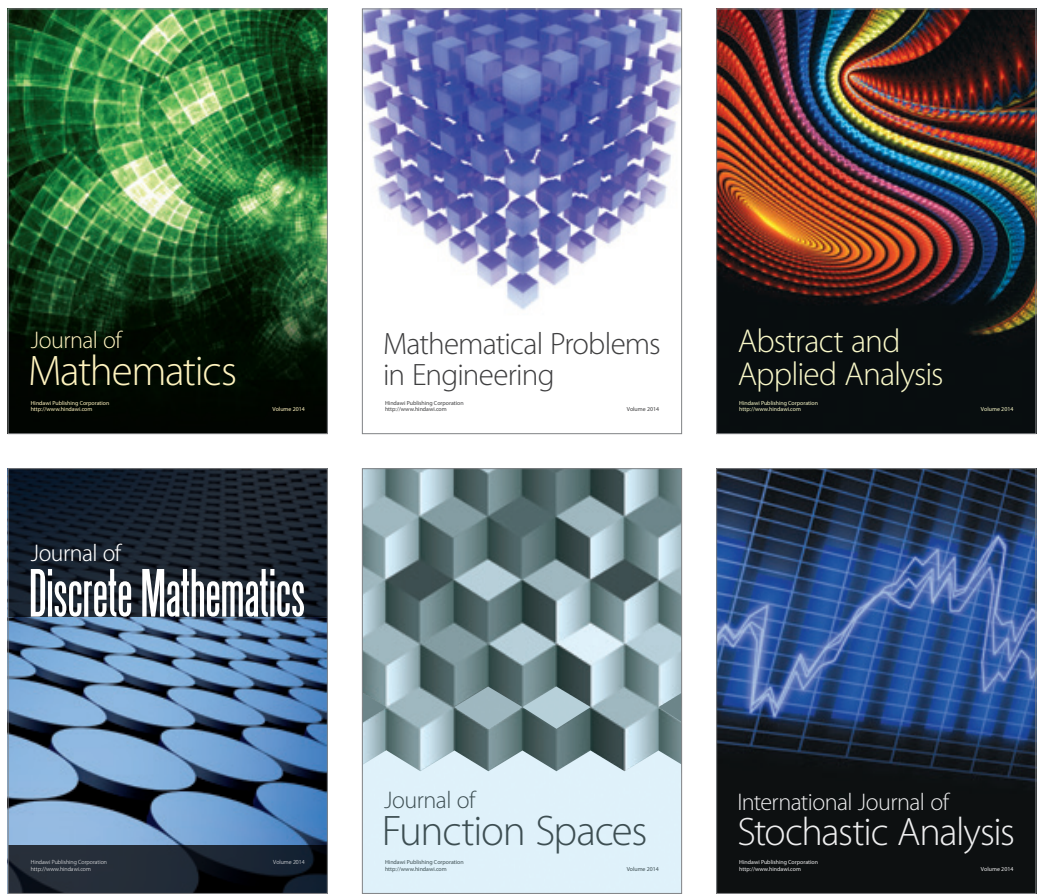

Journal of

Function Spaces

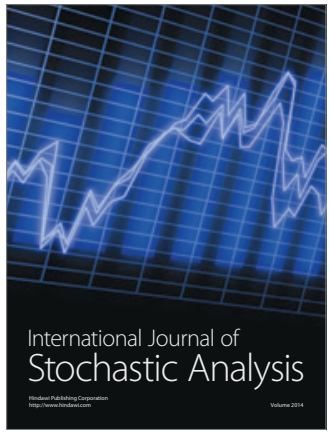

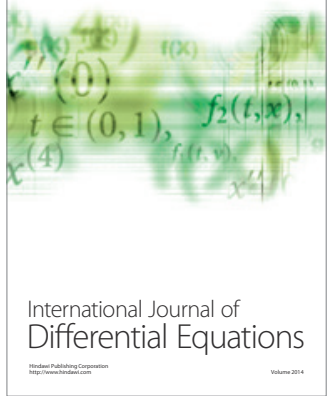
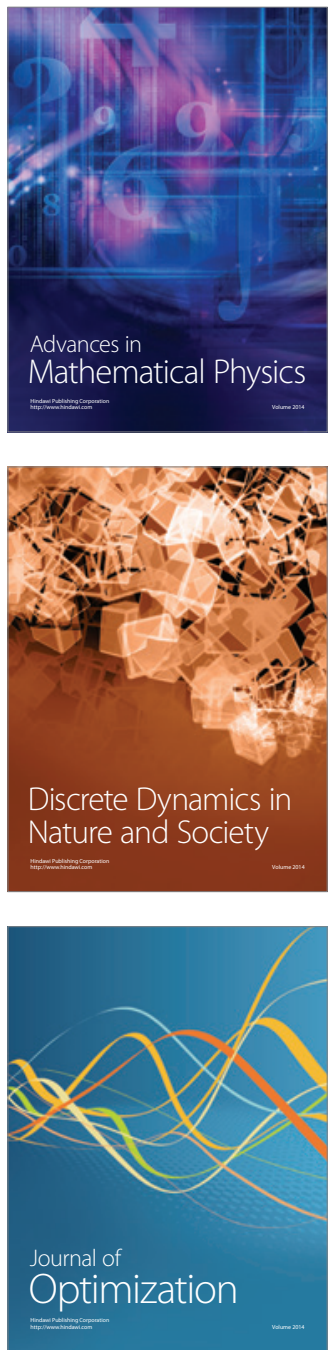